\title{
BRAF Inhibitor PLX8394
}

National Cancer Institute

\section{Source}

National Cancer Institute. BRAF Inhibitor PLX8394. NCI Thesaurus. Code C113330.

An orally bioavailable inhibitor of serine/threonine-protein kinase B-raf (BRAF) protein with potential antineoplastic activity. BRAF inhibitor PLX8394 appears to selectively bind to and inhibit the activity of both wild-type and mutated forms of BRAF, which may subsequently inhibit the proliferation of tumor cells which express mutated forms of BRAF. This inhibitor appears to be effective against tumors that express multiple mutated forms of the kinase and may be an effective therapeutic agent for tumors that are resistant to other BRAF inhibitor therapies that are specific for the BRAF V600E mutant. BRAF, a member of the raf family of serine/threonine protein kinases, plays a role in the regulation of MAP kinase/ERK signaling pathways, which may be constitutively activated due to BRAF gene mutations. Mutated forms of BRAF are associated with a number of neoplastic diseases. 